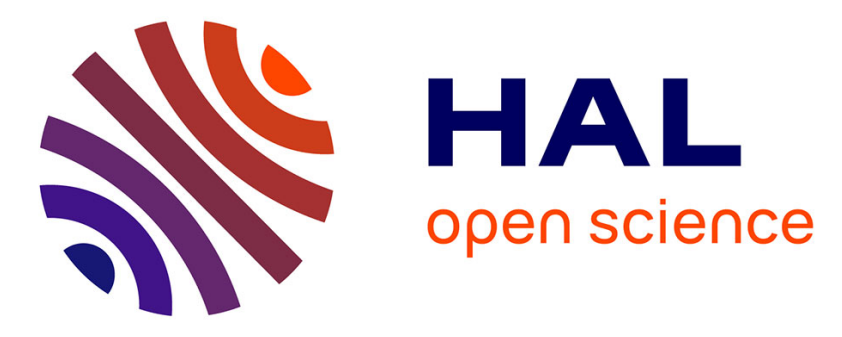

\title{
Influence of cycling cadence on subsequent running performance in triathletes
}

Christophe Hausswirth, Fabrice Vercruyssen, Jeanick Brisswalter, Thierry Bernard, Olivier Bernard, Jean-Marc Vallier

\section{To cite this version:}

Christophe Hausswirth, Fabrice Vercruyssen, Jeanick Brisswalter, Thierry Bernard, Olivier Bernard, et al.. Influence of cycling cadence on subsequent running performance in triathletes. Medicine and Science in Sports and Exercise, 2002, 34 (3), pp.530-536. hal-01759841

\section{HAL Id: hal-01759841 https: / hal-insep.archives-ouvertes.fr/hal-01759841}

Submitted on 5 Apr 2018

HAL is a multi-disciplinary open access archive for the deposit and dissemination of scientific research documents, whether they are published or not. The documents may come from teaching and research institutions in France or abroad, or from public or private research centers.
L'archive ouverte pluridisciplinaire HAL, est destinée au dépôt et à la diffusion de documents scientifiques de niveau recherche, publiés ou non, émanant des établissements d'enseignement et de recherche français ou étrangers, des laboratoires publics ou privés. 


\title{
Influence of cycling cadence on subsequent running performance in triathletes
}

\author{
FABRICE VERCRUYSSEN, JEANICK BRISSWALTER, CHRISTOPHE HAUSSWIRTH, THIERRY BERNARD, \\ OLIVIER BERNARD, and JEAN-MARC VALLIER
}

Université de Toulon-Var, La Garde, FRANCE; Laboratoire de physiologie et biomécanique, INSEP, Paris, FRANCE; and Université de Poitiers, Poitiers, FRANCE

\begin{abstract}
VERCRUYSSEN, F., J. BRISSWALTER, C. HAUSSWIRTH, T. BERNARD, O. BERNARD, and J-M. VALLIER. Influence of cycling cadence on subsequent running performance in triathletes. Med. Sci. Sports Exerc., Vol. 34, No. 3, pp. 530-536, 2002. Purpose: The purpose of this study was to investigate the influence of different cycling cadences on metabolic and kinematic parameters during subsequent running. Methods: Eight triathletes performed two incremental tests (running and cycling) to determine maximal oxygen uptake $\left(\dot{\mathrm{V}}_{2 \max }\right)$ and ventilatory threshold $(\mathrm{VT})$ values, a cycling test to assess the energetically optimal cadence (EOC), three cycle-run succession sessions (C-R, 30-min cycle + 15-min run), and one 45-min isolated run (IR). EOC, C-R, and IR sessions were realized at an intensity corresponding to $\mathrm{VT}+5 \%$. During the cycling bouts of $\mathrm{C}-\mathrm{R}$ sessions, subjects had to maintain one of the three pedaling cadences corresponding to the EOC $(72.5 \pm 4.6 \mathrm{rpm})$, the freely chosen cadence (FCC; $81.2 \pm 7.2 \mathrm{rpm}$ ), and the theoretical mechanical optimal cadence (MOC, $90 \mathrm{rpm}$; Neptune and Hull, 1999). Results: Oxygen uptake $\left(\dot{\mathrm{VO}}_{2}\right)$ increased during the 30-min cycling only at MOC $(+12.0 \%)$ and FCC $(+10.4 \%)$. During the running periods of C-R sessions, $\dot{\mathrm{VO}}_{2}$, minute ventilation, and stride-rate values were significantly higher than during the IR session (respectively, $+11.7 \%,+15.7 \%$, and $+7.2 \%$ ). Furthermore, a significant effect of cycling cadence was found on $\mathrm{VO}_{2}$ variability during the 15-min subsequent run only for MOC $(+4.1 \%)$ and FCC $(+3.6 \%)$. Conclusion: The highest cycling cadences (MOC, FCC) contribute to an increase in energy cost during cycling and the appearance of a $\dot{\mathrm{V}}_{2}$ slow component during subsequent running, whereas cycling at EOC leads to a stability in energy cost of locomotion with exercise duration. Several hypotheses are proposed to explain these results such as changes in fiber recruitment or hemodynamic modifications during prolonged exercise. Key Words: LOCOMOTION, TRIATHLETES, ENERGY COST, CYCLERUN SUCCESSION, CYCLING CADENCE, $\dot{\mathrm{VO}}_{2}$ SLOW COMPONENT, STRIDE RATE
\end{abstract}

I n long-distance multisport activities such as triathlon, in which athletes compete sequentially in swimming, cycling, and running, minimizing energy expenditure while maintaining a high average speed for the entire race is one of the more important determinant of successful performance $(3,22,28)$. However, previous studies conducted on triathletes indicated a significant increase in energy cost of running $(\mathrm{Cr})$ defined as the amount of energy spent per unit distance $(3,12)$, compared with a control run (11-13). In this case, the effects of exercise duration (11) or cycle-run transition $(12,13)$ are often analyzed to explain the greater $\dot{\mathrm{V}}_{2}$ observed at the end of a triathlon. Within this framework, the increase in energy cost with exercise duration is mainly explained by changes in thermoregulation, fiber recruitment, or lipid mobilization (11), and several physiological and biomechanical factors such as a lower ventilatory efficiency (13) and running kinematic variations (12) have been hypothesized to affect $\mathrm{Cr}$ after cycling. Thus, from a performance optimization perspective, one of the determining factors appears to be the possibility for triathletes to reduce these $\mathrm{Cr}$ alterations during the race.

Classically, the adoption of a particular cadence in cycling or running is suggested to minimize the energy cost of these tasks $(3,4,19)$. However, the relationship between the movement frequency and the energy expenditure is different among the activities $(4,19)$. During running, the athlete spontaneously adopts the pattern of locomotion (i.e., stride length-stride rate combination) corresponding to the lowest energy cost (4). In contrast, the free choice of an energetically optimal cadence during cycling is not observed (19). Previous studies have shown that the most economical pedaling cadence for trained or untrained people varied from 50 to $60 \mathrm{rpm}$ (19), whereas cyclists naturally select cycling cadences between 80 and $90 \mathrm{rpm}$ (27). The choice of a particular pedaling cadence has been related to several criteria such as a minimal neuromuscular fatigue (27), a reduction in force application on the cranks, or a minimization of lower-extremity stress (23). Within this framework, Neptune and Hull (21) have calculated in a theoretical approach that the minimum values of the average individual muscle activation, force, and stress quantities occur at a cadence of $90 \mathrm{rpm}$ during a submaximal steady-state cycling.

With respect to the triathlon activity, these observations raise two questions, one concerning the effect of cadence choice on the variability in energy cost of cycling during prolonged exercise (>20 $\mathrm{min}$ ) and the other concerning the influence of this choice on subsequent running performance. Few authors have investigated the effects of cadence choice 

on cycling adaptation during prolonged exercise in cyclists (5) or triathletes (3). Furthermore, results of these studies remain inconsistent, indicating either no effect of pedaling cadence on metabolic efficiency after a 20-min exercise (5) or a significant effect of cadence choice on cycling economy with a shift in freely chosen cadence toward the most economical cadence at the end of a 30-min exercise (3). To the best of our knowledge, no information is available concerning the effects of a particular pedaling cadence choice during a 30-min prolonged exercise on physiological and biomechanical adaptation during subsequent running.

Therefore, the purpose of this experiment is 1) to investigate the effects of three pedaling cadences on the energy cost of cycling with exercise duration $(30 \mathrm{~min})$ and 2 ) to study the influence of these cycling cadences on the energy cost of the subsequent run.

\section{MATERIALS AND METHODS}

Subjects. Subjects were eight well-trained and motivated male triathletes (mean age: $24.0 \pm 3.0 \mathrm{yr}$; mean weight: $71.1 \pm 6.5 \mathrm{~kg}$; mean height: $180.6 \pm 8.1 \mathrm{~cm}$ ) who currently took part in competition at inter-regional level. The average experience of competing in the triathlon was $4.5 \pm 1.5 \mathrm{yr}$, and all subjects were members of the university triathlon team. Before participating in this study, athletes were fully informed about the protocol modalities, and a consent form was obtained before all testing, according to local ethical committee guidelines.

Overview. Each athlete completed seven testing sessions separated by a rest period at least $48 \mathrm{~h}$. Moreover, subjects were asked to abstain from intensive training $24 \mathrm{~h}$ before each experimental session. During these sessions, inside temperature $\left(20^{\circ} \mathrm{C}\right)$ was controlled in the laboratory. The first and second sessions consisted of two incremental tests of $\dot{\mathrm{V}}{ }_{2 \max }$ determination (running and cycling). The third session was used to determine the energetically optimal cadence (EOC) during a cycling test $\left(\mathrm{CT}_{\text {eoc }} ; 3\right)$. The other experimental sessions presented, in random order, were composed of three cycle-run succession (C-R) and one isolated run (IR) sessions.

Ergometers. All experimental cycling bouts were conducted on an electromagnetically braked cycle ergometer (SRM, Jülich, Welldorf, Germany), on which handlebars and racing seat are fully adjustable both vertically and horizontally to reproduce conditions known to subjects from their own bicycles. Moreover, this ergometer was equipped with individual pedals and toe clips allowing subjects to wear their cycling shoes. The SRM system allowed athletes to maintain constant the power output, independent of cycling cadence. In addition, feedback concerning power output, heart rate, speed, and cadence data were continuously available on a screen control. The power output of SRM ergometry system was calculated from the following equation (15):

$$
\text { Power }(\mathrm{W})=\text { Torque }(\mathrm{Nm}) \text { X Angular Velocity }\left(\mathrm{rad} \cdot \mathrm{s}^{-1}\right) \text {. }
$$

Furthermore, all experimental running bouts were performed on a motorized treadmill with a running speed reached in $20 \mathrm{~s}$. The treadmill speed was controlled by a photoelectric cell throughout all tests.

Maximal oxygen uptake $\left(\mathrm{V}^{2}{ }_{2 \max }\right)$ and ventilatory threshold (VT) determinations. Subjects performed two incremental tests in random order, one on the electromagnetically braked ergocycle and one on the treadmill $(0 \%$ grade). These tests were conducted to volitional exhaustion in order to determine task-specific $\dot{\mathrm{VO}}_{2 \max }$ and ventilatory threshold values (29). The incremental tests were designed to bring subjects to exhaustion in 8-12 $\mathrm{min}$. For the treadmill test, the running speed began at $7 \mathrm{~km} \cdot \mathrm{h}^{-1}$ and was then increased by $1 \mathrm{~km} \cdot \mathrm{h}^{-1}$ every $1 \mathrm{~min}$. For the cycle test, after 6 min of warm-up at $100 \mathrm{~W}$ the power output was increased by $30 \mathrm{~W}$ each minute.

During these tests, oxygen uptake $\left(\dot{\mathrm{VO}}_{2}\right)$, minute ventilation $\left(\dot{\mathrm{V}}_{\mathrm{E}}\right)$, and respiratory exchange ratio (RER) were continuously collected with an automated breath-by-breath system (Brainware Metasys, La Valette, France), and heart rate (HR) was monitored using a Polar unit (X-trainer +, Polar Vantage, Kempele, Finland). The criteria used for the determination of $\dot{\mathrm{V}} \mathrm{O}_{2 \max }$ were a plateau in $\dot{\mathrm{V}} \mathrm{O}_{2}$ despite an increase in power output or running speed and an RER above 1.1 or a heart rate over $90 \%$ of the predicted maximal HR. $\dot{\mathrm{V}}{ }_{2 \max }$ was the average of the last three highest $\dot{\mathrm{V}} \mathrm{O}_{2}$ values recorded. In addition, the ventilatory threshold (VT) was determined during the cycling $\left(\mathrm{VT}_{\text {cycle }}\right)$ and running $\left(\mathrm{VT}_{\text {run }}\right)$ tests by using the criteria of an increase in $\dot{\mathrm{V}}_{\mathrm{E}} / \dot{\mathrm{VO}}_{2}$ with no concomitant increase of $\dot{\mathrm{V}}_{\mathrm{E}} / \dot{\mathrm{VCO}}_{2}$ (29).

Determination of the energetically optimal cadence during cycling. The most economical cycling cadence (EOC) was assessed on the SRM system during a submaximal test performed at an intensity corresponding to $5 \%$ above $\mathrm{VT}_{\text {cycle }}\left(73.4 \pm 3.5 \% \dot{\mathrm{VO}}_{2 \text { max cycle }}\right)$. This exercise intensity was chosen to be comparable to those classically reported in previous studies analyzing the simulated cyclerun succession in well-trained triathletes $(12,13,22)$. In addition, this intensity was estimated to be close to the race pace of our triathletes during cycling in an Olympic triathlon. According to previous studies $(3,28)$, this protocol was composed of six submaximal rides (4-min exercise, 4-min rest) corresponding to six cadences presented in random order $(50,65,80,95,110 \mathrm{rpm}$, and the freely chosen cadence). No feedback was given to the subjects concerning their freely chosen cadence (FCC) during the entire ride. The FCC was recorded every $10 \mathrm{~s}$ and calculated as the average cadence during the last 2 min of the ride. During this test $\left(\mathrm{CT}_{\text {eoc }}\right), \dot{\mathrm{V}} \mathrm{O}_{2}, \dot{\mathrm{V}}_{\mathrm{E}}$, and RER values were continuously analyzed from the 2 nd- to the 4 th-min interval of each ride. Based on previous studies $(3,19)$, the relationship between $\dot{\mathrm{VO}}_{2}$ and pedaling cadence for each subject was fitted using a polynomial regression with a quadratic model. The minimum point of the U-shape curve represented the energetically optimal cadence.

Isolated run and cycle-run succession sessions. During the last four sessions, each subject performed in random order an isolated run session (IR) of $45 \mathrm{~min}$ on the 

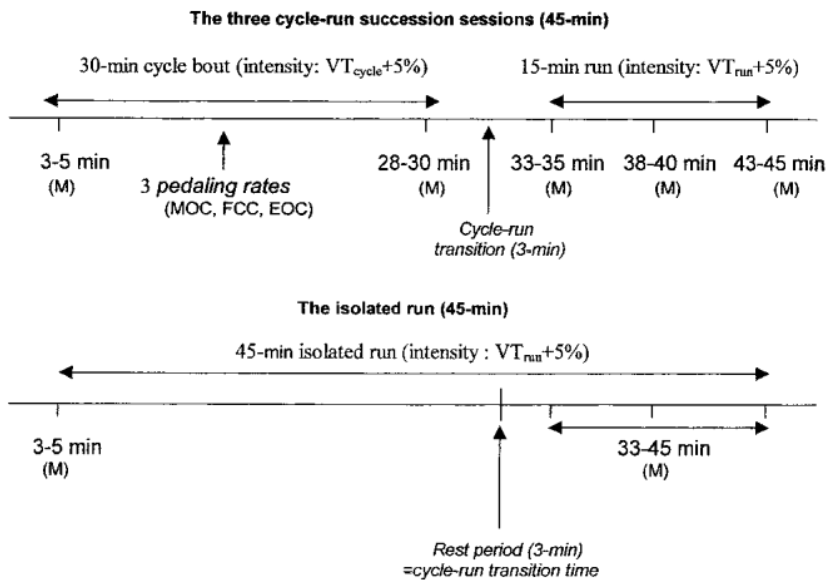

FIGURE 1-Graphic representation of the experimental protocol; M, measurement intervals.

treadmill at a running speed corresponding to $\mathrm{VT}_{\text {run }}+5 \%$ $\left(15.7 \pm 0.7 \mathrm{~km} \cdot \mathrm{h}^{-1}\right.$ and $\left.73.6 \pm 3.6 \% \dot{\mathrm{V}}_{2 \max \text { run }}\right)$ and three cycle-run succession sessions (C-R, 30-min cycle + 15-min run) at an intensity corresponding respectively for the cycling and the running bout to VT $+5 \%$. During the cycling bouts of C-R sessions $(272.1 \pm 17.9 \mathrm{~W}$ and $73.4 \pm 3.5 \%$ $\left.\dot{\mathrm{V}} \mathrm{O}_{2 \max \text { cyle }}\right)$, subjects had to maintain during 30 min one of the three pedaling cadences corresponding to the energetically optimal cadence (EOC) calculated during the third session, the freely chosen cadence (FCC), and the theoretical mechanical optimal cadence (MOC) estimated by Neptune and Hull (21) at $90 \mathrm{rpm}$. After the transition period, subjects performed a 15-min run. To standardize transition time and to install measurement equipment, the transition time between cycling and running was set at $3 \mathrm{~min}$. This time between the two events was slightly greater when compared with those usually recorded in triathlon racing (from $30 \mathrm{~s}$ to $1 \mathrm{~min} ; 13,22$ ) and could have an influence on effects observed during the cycle-run transition. To respect the chronology of this experiment, subjects were stopped after 30 min of the isolated run session during a time corresponding to the transition period of $\mathrm{C}-\mathrm{R}$, and then they realized the last 15 min (Fig. 1).

Physiological parameters measurement. The physiological data $\left(\dot{\mathrm{V}}_{2}, \dot{\mathrm{V}}_{\mathrm{E}}\right.$, RER) were recorded and analyzed during the following intervals: between the 3rd and 5th min of cycling (3-5), between the 28th and 30th min (28-30), between the 33rd and 35th min of subsequent running (33-35), between the 38th and 40th min (38-40) and between the 43rd and 45th min (43-45) (Fig. 1). Furthermore, the oxygen cost of ventilation $\left(\mathrm{VRMO}_{2}\right.$, in $\mathrm{mLO}_{2} \cdot \mathrm{min}^{-1}$ ) was calculated from the work of breathing $\left(\mathrm{W}_{\mathrm{B}}\right.$, in $\mathrm{kg}^{-1} \cdot \mathrm{m}^{-1} \cdot \mathrm{min}^{-1}$ where $\mathrm{m}$ represents meters per minute) using the equations proposed by Coast et al. (6):

$$
\begin{aligned}
\mathrm{WB}= & -0.251+0.0382 \dot{\mathrm{V}}_{\mathrm{E}}+0.00176 \dot{\mathrm{V}}_{\mathrm{E}}^{2} \\
& \dot{\mathrm{VRMO}}_{2}=34.9+7.45 \mathrm{~W}_{\mathrm{B}}
\end{aligned}
$$

Biomechanical parameters measurement. For all experimental conditions, a pressure sensor fixed on the runner's right shoe was used to determine the period be- tween two ground contacts for the same foot. From this signal, the stride duration was continuously recorded and stride pattern characteristics (i.e., stride rate: SR and stride variability: SV) were calculated during the first $5 \mathrm{~min}(0-5$ $\mathrm{min}$ ) and the last $5 \mathrm{~min}(10-15 \mathrm{~min})$ of each running bout.

Statistical analysis. All data were expressed as mean \pm standard deviation (SD). The locomotor pattern variability during running was described using the coefficient of variation (SD/mean X 100) for each athlete (3). A two-way variance analysis plan $(2 \times 3)$ for repeated measures was performed to analyze the effect of the period time and the cycling cadence by using $\dot{\mathrm{VO}}_{2}, \dot{\mathrm{V}}_{\mathrm{E}}$, RER, SR, and $\mathrm{SV}$ values as dependant variables. For this analysis, the stride variability (in \%) was analyzed after an arcsine transformation. Newman-Keuls post hoc test was used to determine differences among all pedaling cadences and periods during exercise. A paired $t$-test was used to analyze a) differences in $\dot{\mathrm{V}} \mathrm{O}_{2 \max }, \dot{\mathrm{V}}_{\mathrm{Emax}}$, and $\dot{\mathrm{V}} \mathrm{O}_{2}$ at VT values between the two incremental tests and $b$ ) variations between the energetically optimal cadence and the freely chosen cadence during $\mathrm{CT}_{\text {eoc }}$. The 0.05 level of significance was used for all statistical procedures.

\section{RESULTS}

Maximal tests. The mean data for the maximal parameters recorded during the two incremental tests are presented in Table 1. No significant differences $(P>0.05)$ were found concerning $\dot{\mathrm{V}} \mathrm{O}_{2 \max }, \dot{\mathrm{V}}_{\mathrm{Emax}}$, and $\dot{\mathrm{V}} \mathrm{O}_{2}$ at VT values recorded during the incremental cycling and running tests. These results indicate the homogeneity of aerobic aptitude of our triathletes whatever the locomotion mode.

The energetically optimal cadence determination. The quadratic trend for the description of the $\dot{\mathrm{V}} \mathrm{O}_{2}-$ cadence relationship was found in all subjects, and the mean value of regression coefficient was $r 0.80 \pm 0.2$. The mathematical determination of the mean EOC (lower point) was identified at $72.3 \pm 5.0 \mathrm{rpm}$ (range $63.5-78.1 \mathrm{rpm}$ ). A significant difference wasidentified between EOC andFCC during $\mathrm{CT}_{\text {eoc }}(72.3 \pm 5.0$ vs $81.9 \pm 11.7 \mathrm{rpm}, P<0.05)$.

\section{Cycling Bouts of C-R}

Biomechanical parameters. The mean values in pedaling cadences recorded during the 30-min exercise were for MOC, FCC, and EOC bouts: $90.2 \pm 0.8,81.2 \pm 7.2$, and $72.5 \pm 4.6 \mathrm{rpm}$, respectively. The statistical analysis indicated a significant difference between the mean values in the three cycling cadences $(P<0.05)$. No significant variation

TABLE 1. Subjects physiological characteristics during the two incremental tests.

\begin{tabular}{lcc}
\multicolumn{1}{c}{ Parameters } & Running Test & Cycling Test \\
\hline$\dot{\mathrm{VO}}_{2 \max }$ & $69.9 \pm 5.5$ & $68.7 \pm 3.2$ \\
$\dot{\mathrm{V}}_{\mathrm{Emax}}\left(\mathrm{mL} \cdot \mathrm{min}^{-1} \cdot \mathrm{kg}^{-1}\right)$ & $188.7 \pm 7.3$ & $184.8 \pm 11.9$ \\
$\mathrm{HR}$ & $190.1 \pm 5.7$ & $186.4 \pm 6.9$ \\
$\mathrm{VT}\left(\% \dot{\mathrm{VO}}_{2 \max }\right)$ & $70.1 \pm 3.4$ & $69.9 \pm 3.3$ \\
\hline
\end{tabular}

$\overline{\mathrm{V}} \mathrm{O}_{2 \max }$, maximal oxygen uptake; $\dot{\mathrm{V}}_{\mathrm{Emax}}$ : maximal ventilation; $\mathrm{HR}_{\max }$, maximal heart rate; VT, ventilatory threshold.

Values are expressed as mean \pm SD. 
TABLE 2. Changes in mean oxygen uptake $\left(\dot{\mathrm{VO}}_{2}\right)$, minute ventilation $\left(\dot{\mathrm{V}}_{\mathrm{E}}\right)$, and respiratory exchange ratio (RER) during the three cycle-run succession sessions (MOC-run, FCCrun, EOC-run) and the isolated run session (IR) at different time intervals: 0-5 min, 28-30 min, 33-35 min, 38-40 min, and 43-45 min.

\begin{tabular}{|c|c|c|c|c|}
\hline \multicolumn{2}{|c|}{ Experimental Conditions } & \multicolumn{3}{|c|}{ Physiological Parameters } \\
\hline Testing Sessions & $\begin{array}{l}\text { Measurement } \\
\text { Intervals }\end{array}$ & $\begin{array}{c}\mathrm{VO}_{2} \\
\left(\mathrm{~mL} \cdot \mathrm{kg}^{-1} \cdot \mathrm{min}^{-1}\right)\end{array}$ & VE $\left(L \cdot \min ^{-1}\right)$ & RER \\
\hline \multirow{5}{*}{$\begin{array}{l}\text { Cycling MOC } \\
\text { (running bout) }\end{array}$} & $3-5 \min$ & $52.3 \pm 5.6$ & $113.0 \pm 10.6$ & $1.02 \pm 0.07$ \\
\hline & $28-30 \mathrm{~min}$ & $58.6 \pm 6.5^{a d}$ & $142.5 \pm 10.7^{a}$ & $1.01 \pm 0.04$ \\
\hline & $33-35 \mathrm{~min}$ & $56.6 \pm 5.2^{b d}$ & $135.7 \pm 10.5^{b}$ & $0.99 \pm 0.04$ \\
\hline & $38-40 \mathrm{~min}$ & $57.8 \pm 4.6^{b d}$ & $139.0 \pm 9.8^{b}$ & $1.00 \pm 0.04$ \\
\hline & $43-45 \mathrm{~min}$ & $58.9 \pm 5.1^{b c d}$ & $142.1 \pm 12.2^{b}$ & $1.00 \pm 0.04$ \\
\hline \multirow{5}{*}{$\begin{array}{l}\text { Cycling FCC (running } \\
\text { bout) }\end{array}$} & $3-5 \min$ & $51.6 \pm 4.8$ & $109.3 \pm 16.0$ & $1.02 \pm 0.06$ \\
\hline & $28-30 \mathrm{~min}$ & $57.0 \pm 3.4^{a d}$ & $122.5 \pm 12.4$ & $0.99 \pm 0.04$ \\
\hline & $33-35 \mathrm{~min}$ & $56.9 \pm 4.7^{b}$ & $132.1 \pm 17.9^{b}$ & $0.99 \pm 0.06$ \\
\hline & $38-40 \mathrm{~min}$ & $58.7 \pm 3.8^{b d}$ & $135.1 \pm 21.1^{b}$ & $0.99 \pm 0.05$ \\
\hline & $43-45 \mathrm{~min}$ & $59.0 \pm 4.8^{b c d}$ & $135.4 \pm 19.0^{b}$ & $0.99 \pm 0.06$ \\
\hline \multirow{5}{*}{$\begin{array}{l}\text { Cycling EOC (running } \\
\text { bout) }\end{array}$} & $3-5 \min$ & $50.6 \pm 4.5$ & $110.2 \pm 10.0$ & $1.02 \pm 0.09$ \\
\hline & $28-30 \mathrm{~min}$ & $53.3 \pm 5.2$ & $118.6 \pm 15.1$ & $0.99 \pm 0.05$ \\
\hline & 33-35 min & $54.4 \pm 5.1^{b}$ & $131.3 \pm 15.8^{b}$ & $0.99 \pm 0.05$ \\
\hline & $38-40 \mathrm{~min}$ & $55.9 \pm 4.4^{b}$ & $134.0 \pm 12.7^{b}$ & $1.00 \pm 0.03$ \\
\hline & $43-45 \mathrm{~min}$ & $55.7 \pm 3.9^{b}$ & $136.6 \pm 16.6^{b}$ & $1.01 \pm 0.06$ \\
\hline \multirow[t]{2}{*}{ Isolated run } & $3-5 \mathrm{~min}$ & $50.7 \pm 3.6$ & $110.5 \pm 18.1$ & $1.00 \pm 0.05$ \\
\hline & $33-45 \mathrm{~min}$ & $51.0 \pm 2.7$ & $117.2 \pm 17.7$ & $0.99 \pm 0.05$ \\
\hline
\end{tabular}

a Significantly different from the 3-5 min interval $(P<0.05)$.

${ }^{b}$ Significantly differentfrom the isolated run $(P<0.05)$.

'Significantly different from the 33-35 min interval $(P<0.05)$.

${ }^{d}$ Significantly different from the same period at EOC $(P<0.05)$.

Values are expressed as means $\pm S D$.

in FCC was found during the 30-min cycling (respectively for the 3- to 5-min and 28- to 30-min intervals: $81.1 \pm 7.5$ vs $81.3 \pm 7 \mathrm{rpm}, P>0.05)$. Lastly, no significant differences in FCC and EOC were observed between the third session $\left(\mathrm{CT}_{\text {eoc }}\right)$ and $\mathrm{C}-\mathrm{R}$ sessions $(P>0.05)$.

Physiological parameters. Table 2 shows the changes in physiological parameters during the experimental protocol. A significant effect of the exercise duration was observed on $\mathrm{LIVO}_{2}$ during the first 30-min $\left(\dot{\mathrm{VO}}_{2(28-30)^{-}}\right.$ $\left.\dot{\mathrm{VO}}_{2(3-5)}, P<0.05\right)$ only during MOC and FCC bouts $(+12.0 \%$ and $+10.4 \%$, respectively), whereas no significant difference in $\mathrm{LIVOO}_{2}$ was found at $\operatorname{EOC~}(P>0.05)$. During the 30 -min cycling, $\dot{\mathrm{V}} \mathrm{O}_{2}$ values recorded during EOC were significantly lower than those reported in the other conditions $(P<0.05)$. Furthermore, a significant increase in $\mathrm{LI} \dot{\mathrm{V}}_{\mathrm{E}}$ during the $30 \min \left(\dot{\mathrm{V}}_{\mathrm{E}(28-30)}\right)^{-} \dot{\mathrm{V}}_{\mathrm{E}(3-5)}$ was identified only during MOC $(+26.1 \% ; P<0.05)$. Within this framework, the cost of ventilation $\left(\mathrm{VRMO}_{2}\right.$, in $\mathrm{mLO}_{2} \cdot \mathrm{min}^{-1}$ ) significantly increased between the 3- to 5$\min$ and 28 - to 30 -min intervals $(+48.7 \%)$ and represented $26.8 \%$ of $\dot{\mathrm{VO}}_{2}$ rise.

\section{Cycle-Run Succession Sessions}

Biomechanical parameters. The results are presented in Table 3. Whatever the prior cycling cadence, the stride rate (SR) recorded during the subsequent run was significantly higher than during the isolated run $(+7.2 \%)$. No significant difference in stride variability (SV) was found whatever the condition $(P>0.05)$.

Physiological parameters. In agreement with previous results (12), no significant variation in mean $\dot{\mathrm{VO}}_{2}$ and $\dot{\mathrm{V}}_{\mathrm{E}}$ was observed during the IR session. Conversely, a significant effect of a prior cycling exercise was observed on
$\dot{\mathrm{V}}_{2}$ values during the subsequent run $(P<0.05$, Table 2$)$. In comparison with the isolated run, oxygen uptake and ventilation values were significantly higher whatever the prior pedaling cadence $\left(\dot{\mathrm{VO}}_{2}:+11.7 \%\right.$ and $\dot{\mathrm{V}}_{\mathrm{E}}:+15.7 \%, P$ $<0.05)$. The cost of ventilation $\left(\mathrm{VRMO}_{2}\right.$, in $\left.\mathrm{mLO}_{2} \cdot \mathrm{min}^{-1}\right)$ significantly increased during the run of C-R sessions when compared with the IR session $(+39.6 \%)$ and represented $26.3 \%$ of $\dot{\mathrm{VO}}_{2}$ rise. Furthermore, a significant increase in $\mathrm{LIV} \mathrm{V}_{2}$ during the $15-\mathrm{min}$ subsequent run $\left(\dot{\mathrm{VO}}_{2(43-45)^{-}}\right.$ $\dot{\mathrm{VO}}_{2(33-35)}$ was identified during the MOC-run and FCC-run sessions $(+4.1 \%$ and $+3.6 \%$ respectively, $P<0.05)$. In contrast, no rise in $\mathrm{LIVO}_{2}$ was observed during the EOC-run session, and the $\dot{\mathrm{VO}}_{2}$ values recorded during this condition were significantly lower than those obtained in the other conditions $(P<0.05)$.

\section{DISCUSSION}

The main findings of this study indicate a significant effect of pedaling cadence choice on oxygen uptake variability with exercise duration during cycling bouts and during the subsequent run of cycle-run succession sessions. Furthermore, our results confirm the significant alteration in energy cost of running $(\mathrm{Cr})$ after a prior cycling bout when compared with an isolated run session.

Cycling economy and exercise duration. The present results show a decrease in cycling economy $\left(\mathrm{C}_{\mathrm{E}}\right.$, i.e., $\dot{\mathrm{V}}_{2}$ during submaximal cycling at a given work rate) after a 30-min exercise performed at the theoretical mechanical optimal cadence (MOC, $90 \mathrm{rpm}$; 21) and at the freely chosen cadence (FCC, $81.2 \pm 7.2 \mathrm{rpm}$ ). In contrast, no significant variation in $\mathrm{C}_{\mathrm{E}}$ was observed at the energetically optimal cadence (EOC, $72.5 \pm 4.6 \mathrm{rpm}$ ) with exercise duration. To 
TABLE 3. Stride characteristics during the 15-min run of cycle-run succession sessions (MOC-run, FCC-run, EOC-run) and the isolated run session (IR) at two time intervals: $0-5 \mathrm{~min}$ and $10-15 \mathrm{~min}$.

\begin{tabular}{ccccc}
\hline \multicolumn{2}{c}{ Experimental Conditions } & & \multicolumn{2}{c}{ Biomechanical Parameters } \\
\cline { 5 - 5 } $\begin{array}{c}\text { Testing } \\
\text { Sessions }\end{array}$ & $\begin{array}{c}\text { Measurement } \\
\text { Intervals }\end{array}$ & & $\begin{array}{c}\text { Stride Rate } \\
\mathbf{( H z )}\end{array}$ & $\begin{array}{c}\text { Stride } \\
\text { Variability (\%) }\end{array}$ \\
\hline MOC-run & $0-5 \mathrm{~min}$ & & $1.44 \pm 0.06^{a}$ & $7.96 \pm 2.83$ \\
& $10-15 \mathrm{~min}$ & & $1.42 \pm 0.06^{a}$ & $8.38 \pm 2.22$ \\
FCC-run & $0-5 \mathrm{~min}$ & & $1.41 \pm 0.02^{a}$ & $11.49 \pm 4.65$ \\
& $10-15 \mathrm{~min}$ & & $1.40 \pm 0.04^{a}$ & $11.02 \pm 3.56$ \\
EOC-run & $0-5 \mathrm{~min}$ & & $1.44 \pm 0.05^{a}$ & $8.83 \pm 3.46$ \\
& $10-15 \mathrm{~min}$ & & $1.40 \pm 0.06^{a}$ & $9.30 \pm 2.25$ \\
Isolated run & $0-5 \mathrm{~min}$ & & $1.31 \pm 0.03$ & $11.42 \pm 3.73$ \\
& $10-15 \mathrm{~min}$ & & $1.33 \pm 0.05$ & $11.86 \pm 3.89$ \\
\hline
\end{tabular}

Significantly different from the isolated run at the same period $(P<0.05)$.

Values are expressed as means \pm SD.

the best of our knowledge, little information is available concerning the effect of pedaling cadence choice on $\mathrm{C}_{\mathrm{E}}$ during prolonged exercise $(3,5)$. In a first study, Coast et al. (5) have not reported any cadence choice effect (40-120 rpm) on $\mathrm{C}_{\mathrm{E}}$ during a 20 -min exercise at $85 \% \dot{\mathrm{VO}}_{2 \max }$ (approximately $300 \mathrm{~W}$ ) in five cyclists. However, Brisswalter et al. (3) reported an effect of cycling cadence $(50-110 \mathrm{rpm})$ on $\mathrm{C}_{\mathrm{E}}$ during a 30-min cycling exercise conducted at $80 \%$ of the maximal power output $(291.0 \pm 25 \mathrm{~W})$ in 10 triathletes. Our values recorded for a power output corresponding to $272.1 \pm 17.9 \mathrm{~W}$ are in agreement with this previous study and indicate a significant effect of pedal cadence choice on $\dot{\mathrm{VO}}_{2}$ variability during a 30-min cycling bout.

During moderate- to high-intensity exercise, one of the factors often used to explain changes in $\mathrm{V}_{2}$ with exercise duration and pedal cadence manipulation is a modification in muscle fiber recruitment $(3,24)$. Within this framework, Woledge (30) has suggested that the supplementation of Type I by Type II fibers during prolonged exercise would be linked to a decrease in thermodynamic muscle efficiency leading to an increase in energy cost. Thus, in our study, one first hypothesis could relate the increase in $\mathrm{LIVO}_{2}$ at high pedal cadences (>80 rpm) during the first 30-min of cycling to an additional recruitment of Type II muscle fibers, which have a lower muscle efficiency (i.e., higher energy phosphate produced per oxygen molecule consumed) than Type I fibers (30). On the contrary, no variation in cycling economy was observed after a 30-min exercise at EOC, providing support for the hypothesis that the adoption of this cadence in subjects could be related to the greater participation of Type I fibers. Nevertheless, the relationship between pedaling cadence, muscle fibers recruitment (based on iEMG), and cycling economy is not clearly identified. Therefore, it could be interesting in such studies to analyze simultaneously the cycling economy variability and the activity of the larger working muscle mass involved in cycling at different cadences (range 50-110 rpm) during prolonged exercise.

In this study, our triathletes spontaneously choose a pedaling cadence $(81 \mathrm{rpm})$ significantly higher than the most economical cadence $(73 \mathrm{rpm})$. The choice of high pedaling cadence leads to an increase in oxygen uptake classically related to an increase in internal work for repetitive limb movements $(8,26)$ and/or to an increase in the ventilation cost (6). On the one hand, Francescato et al. (8) have indicated that the fraction of overall $\mathrm{VO}_{2}$ consumption due to internal work for a subject pedaling at $100 \mathrm{~W}$ and $60 \mathrm{rpm}$ was about 0.2 while this fraction was about 0.6 at $100 \mathrm{rpm}$. On the other hand, for mean group values, our results show a significant increase of $\dot{\mathrm{V}}_{\mathrm{E}}$ only at the end of MOC bout. Based on the equations proposed by Coast et al. (6), the cost of ventilation estimated from the increase in the work of

breathing $\left(\mathrm{W}_{\mathrm{B}}\right)$ could explain approximately only $26.8 \%$ of the $\mathrm{VO}_{2}$ increase with exercise duration.

Our data confirm previous results indicating that minimization of aerobic demand is not a key determinant of preferred cadence choice in trained subjects $(3,19,26,27)$. For cycling exercises of short duration, an apparent conflict is systematically observed between the energetically optimal cadence and the self-selected cadence in experienced cyclists, trained runners $(19,27)$, or triathletes (3). Several hypotheses are advanced to explain the adoption of high pedaling cadences. On the one hand, it has been reported that the peak pedal force in cyclists reached a minimum value for cadences between 90 and $100 \mathrm{rpm}$ (23), suggesting a pedaling skill to reduce pedal force at the highest pedaling cadences (26). Within this framework, Takaishi et al. (27) hypothesized that the reason that cyclists adopt a higher cadence is closely related to the reduction of neuromuscular fatigue in working muscles (i.e., minimum value of muscles iEMG) rather than the economy (i.e., less energy expenditure) for pedaling-exercise. On the other hand, Marsh and Martin (19) have suggested that aerobic fitness level may become important in preferred cadence selection because trained runners with no cycling experience but a history of endurance training selected high pedaling cadences comparable to those reported in experienced cyclists. However, for long-duration cycling exercise (>30 min), this discrepancy between the energetically optimal cadence and the selfselected cadence is not systematically observed in triathletes $(17,28)$. Recent studies have indicated a reduction in FCC toward the most economical cadence after 1-h and 2-h cycling exercise at a constant power output $(17,28)$. Further multidisciplinary studies seem therefore necessary to study factors that decide preferred cadence especially during prolonged exercise.

Cycling exercise and energy cost of the subsequent run. According to previous results (11-13), the energy cost of running $\left(\mathrm{Cr}\right.$, i.e., $\dot{\mathrm{V}} \mathrm{O}_{2}$ during submaximal running at a given intensity) was significantly higher after cycling bouts when compared with an isolated run session $(+11.7 \%)$. The mean relative values of $\dot{\mathrm{VO}}_{2}$ for IR and C-R sessions ranged from 74.5 to $83 \% \dot{\mathrm{VO}}_{2 \max }$, respectively. These results recorded after $45 \mathrm{~min}$ of exercise could be related to those reported by several authors, comparing either an overground triathlon race or a simulated cycle-run succession in laboratory with an isolated run (respectively for IR vs C-R: 73 and 77 vs 78 and $83 \% \dot{V}_{2 \max }$ ) (11-13).

Within this framework, the change in stride rate-stride length combination is often suggested to account for a substantial portion in the $\mathrm{Cr}$ variability (4). In our study, the $7.2 \%$ increase in stride rate during $\mathrm{C}-\mathrm{R}$ sessions may be 
linked to an increase in mechanical work and therefore to the increase of energy cost of running. This result is in agreement with previous studies that have showed, with the appearance of fatigue, a significant increase in stride rate and a decrease in stride length to maintain constant the running speed (7). This could suggest in our study that when subjects realized a cycle exercise just before running, the fatigue process in the lower limb musculature is important and could explain, in part, the difference in energy cost between the isolated run and the cycle-run succession session.

Cycling cadence choice and energy cost variability in running. One of the most interesting findings of this study is the observation of a continual increase in $\mathrm{V}_{2}$ during the 15 -min run after the highest pedal cadences (MOC, FCC). For exercise lasting less than 15 min, the continual increase in $\dot{\mathrm{V}}_{2}$ beyond the $3 \mathrm{rd}$ min of exercise (i.e., delayed steady state) has been termed the slow component of oxygen uptake kinetics $\left(\dot{\mathrm{V}} \mathrm{O}_{2 \mathrm{SC}}\right)$ $(1,2,14,24)$. According to previous studies, the work rate of exercise associated with the appearance of a $\dot{\mathrm{VO}}_{2 \mathrm{SC}}$ is above lactate or ventilatory thresholds (i.e., heavy exercise) $(2,14,24)$. Postulated mechanisms responsible for this $\mathrm{VO}_{2 \mathrm{SC}}$ include rising muscle temperature (i.e., $\mathrm{Q}_{10}$ effect), cardiac and ventilatory muscle work, lactate kinetic, catecholamines, and recruitment of less-efficient Type II muscle fibers (24).

In our study, one possible explanation for the appearance of a $\dot{\mathrm{VO}}_{2 \mathrm{SC}}$ during the subsequent run (MOC-run and FCCrun) could be the difference in metabolic level of exercise recorded at the end of MOC and FCC bouts. This first hypothesis could be linked to previous studies $(1,25,27)$ which suggest that a relationship exists between the appearance of a $\dot{\mathrm{V}} \mathrm{O}_{2 \mathrm{SC}}$ and the progressive greater use of fasttwitch motor units during a 15-min bout of cycling performed at a high intensity.

Classically, it has been reported that a progressive increase in exercise intensity would be expected to recruit a larger population of Type II fibers $(24,25,27)$. In our study, the work intensity at the end of cycling bout ranges from $78 \% \dot{\mathrm{VO}}_{2 \max }$ for the EOC-run session to $84-85 \%$ $\mathrm{VO}_{2 \max }$ for MOC-run and FCC-run sessions. Thus, we suggest that more Type II fibers are recruited at the start of the running session after the FCC and MOC bouts. Conversely, our results show a lower energy cost during the 30-min cycling exercise and during the 15-min subsequent run session when subjects adopt the energetically optimal cadence at the same power output. Because of the lower metabolic intensity (i.e., $78 \% \dot{\mathrm{VO}}_{2 \max }$ after cycling exercise), we hypothesized that the adoption of EOC induce a lower proportion of Type II fibers during the 30-min exercise. These hypothesis could explain, for a part, a reduction in $\dot{\mathrm{VO}}_{2 \mathrm{SC}}$ during the subsequent run and appear to be in agreement with results of Barstow et al. (1), who have reported a correlation between the reduction of $\dot{\mathrm{VO}}_{2 \mathrm{SC}}$ and the percentage of Type I fibers in the vastus lateralis. Nevertheless, this relationship between the $\dot{\mathrm{VO}}{ }_{2 \mathrm{SC}}$ and the nature of fiber recruitment has not been systematically validated.

Recently, Lucia et al. (18) have reported the appearance of a $\dot{\mathrm{V}} \mathrm{O}_{2 \mathrm{SC}}$ without any changes in EMG data (rms-EMG and mean power frequency) recorded during a 20-min exercise at a high power output in professional cyclists. Furthermore, most of the previous studies have investigated the mechanisms underlying the $\dot{\mathrm{V}} \mathrm{O}_{2 \mathrm{SC}}$ during an isolated running (2) or a cycling exercise (1), indicating a larger $\dot{\mathrm{V}}_{2 \mathrm{SC}}$ in cycling when compared with running (14). Within this framework, to the best of our knowledge, no information is available concerning the $\dot{\mathrm{V}} \mathrm{O}_{2 \mathrm{SC}}$ during a run session after a cycling exercise. During the last decade, some authors have analyzed the effects of prior high-or low-intensity cycling on $\dot{\mathrm{VO}}_{2 \mathrm{SC}}$ of subsequent high-intensity cycling exercise $(9,16)$. These authors have showed a significant reduction in $\dot{\mathrm{V}} \mathrm{O}_{2 \mathrm{SC}}$ (between the 3rd min and the 6th min) after a prior high-intensity exercise. Gerbino et al. (9) have suggested that this reduction in $\dot{\mathrm{VO}}_{2 \mathrm{SC}}$ during the second cycling exercise could be explained by hemodynamic modifications leading to an improvement of muscle perfusion.

According to this hypothesis, one explanation of our results could be the difference in muscle perfusion between a run realized after cycling and an isolated run. For instance, Matsui et al. (20) have measured muscular blood flow immediately after treadmill and bicycle exercise and reported that the blood flow in the thigh after a cycling exercise test was significantly higher than that in the calf. In addition, these authors reported no significant difference in blood flow between thigh and calf after treadmill running exercise. Moreover, during cycling Gotshall et al. (10) have suggested a muscle overperfusion with increasing pedaling cadences (from 50 to $110 \mathrm{rpm}$ ) during a 5-min cycling exercise. This improved perfusion of the working musculature consequent to the higher cycling cadence was explained by an increase in muscle blood flow and a decrease in systemic vascular resistance. Therefore, based on these previous results we hypothesize that during cycling, activated muscles (i.e., vastus lateralis and medialis) $(26,27)$ become overperfused with increasing pedaling cadence (10). In contrast, the muscles used in running (i.e., muscles of the calf) become relatively less perfused during the cycling task. Later, during running, these previously less active calf muscles become active, accounting for the greater $\dot{\mathrm{VO}}_{2 \mathrm{SC}}$ during the subsequent run. Future research is necessary to validate this previous hypothesis because of the inconsistency of results in this area.

In conclusion, results of this study indicate that prior high cycling cadences (MOC, FCC) contribute to the appearance of a $\dot{\mathrm{VO}}_{2}$ slow component during subsequent running. However, the choice of the energetically optimal cadence leads to a reduction in energy cost of locomotion during cycling and the subsequent run. Thus, we suggest that cycling near the energetically optimal cadence is beneficial in term of $\mathrm{VO}_{2}$ after 30 min and could become a strategy in anticipation of the running performance. In the context of multisport activities such as triathlon or duathlon, further investigations are necessary to 
identify metabolic and neuromuscular mechanisms underlying relationships between prior cycling cadences and energy cost of running variability during subsequent running. Also missing is the need for future performance-based evaluations of different cycling to run strategies.

\section{REFERENCES}

1. Barstow, T. J., A. M. Jones, P. H. Nguyen, and R. Casaburi. Influence of muscle fiber type and pedal frequency on oxygen uptake kinetics of heavy exercise. J. Appl. Physiol. 81:1642-1650, 1996.

2. Bernard, O., F. Maddio, S. Ouattara, et al. Influence of the oxygen uptake slow component on the aerobic energy cost of high-intensity submaximal treadmill running in humans. Eur. J. Appl. Physiol. 78:578-585, 1998.

3. Brisswalter, J., C. Hausswirth, D. Smith, F. Vercruyssen, and J. M. VALLIER. Energetically optimal cadence vs. freely chosen cadence during cycling: effect of exercise duration. Int. J. Sports Med. 20:1-5, 2000.

4. Cavanagh, P. R., and K. R. Williams. The effect of stride length variation on oxygen uptake during distance running. Med. Sci. Sports Exerc. 14:30-35, 1982.

5. CoAst, J. R., R. H. Cox, and H. G. Welch. Optimal pedalling rate in prolonged bouts of cycle ergometry. Med. Sci. Sports Exerc. 18:225-230, 1986.

6. Coast, J. R., S. A. Rasmussen, K. M. Krause, J. A. O’Kroy, R. A. LoY, and J. RHODES. Ventilatory work and oxygen consumption during exercise and hyperventilation. J. Appl. Physiol. 74:793798, 1993.

7. Elliot, B. C., and A. D. Roberts. A biomechanical evaluation of the role of fatigue in middle-distance running. Can. J. Appl. Sports Sci. 5:203-207, 1980

8. Francescato, M. P., M. Girardis, and P. E. Di Prampero. Oxygen cost of internal work during cycling. Eur. J. Appl. Physiol. 72: 51-57, 1995.

9. Gerbino, A., S. A. WARD, and B. J. Whipp. Effects of prior exercise on pulmonary gas-exchange kinetics during high-intensity exercise in humans. J. Appl. Physiol. 80:99-107, 1996.

10. Gotshall, R. W., T. A. Bauer, and S. L. Fahmer. Cycling cadence alters exercise hemodynamics. Int. J. Sports Med. 17:17-21, 1996.

11. Guezennec, C. Y., J. M. Vallier, A. X. Bigard, and A. Durey. Increase in energy cost of running at the end of a triathlon. Eur. J. Appl. Physiol. 73:440-445, 1996.

12. Hausswirth, C., A. X. Bigard, and C. Y. Guezennec. Relationships between mechanics and energy cost of running at the end of a triathlon and a marathon. Int. J. Sports Med. 18:330-339, 1997.

13. Hue, O., D. Le Gallais, D. Chollet, A. Boussana, and C. PrÉFAut. The influence of prior cycling on biomechanical and cardiorespiratory response profiles during running in triathletes. Eur. J. Appl. Physiol. 77:98-105, 1998.

14. Jones, A. M., and A. M. McConnell. Effect of exercise modality on oxygen uptake kinetics during heavy exercise. Eur. J. Appl. Physiol. 80:213-219, 1999.
The authors gratefully acknowledge all the triathletes who took part of the experiment for their high cooperation and motivation.

Address for correspondence: F. Vercruyssen, Unité Ergonomie Sportive et Performance, Université de Toulon-Var, Avenue de L'université, BP 132, F-83957 La Garde cedex, France; E-mail: vercruyssen@univ-tln.fr.

15. Jones, S. M., and L. PAssfield. The dynamic calibration of bicycle power measuring cranks. In: The Engineering of Sport, S. J. Haake Sj (Ed.). Oxford: Blackwell Science, 1998, pp. 265-274.

16. Koppo, K., and J. BouckaErT. In humans the oxygen uptake is reduced by prior exercise of high as well as low intensity. Eur. J. Appl. Physiol. 83:559-565, 2000.

17. Lepers, R., C. Hausswirth, N. Maffiuletti, J. Brisswalter, and J. VAN HoECKE. Evidence of neuromuscular fatigue after prolonged cycling exercise. Med. Sci. Sports Exerc. 32:1880-1886, 2000.

18. Lucia, A., J. Hoyos, and J. L. Chicharro. The slow component of $\dot{\mathrm{VO}}_{2}$ in professional cyclists. Br. J. Sports Med. 34:365-374, 2000.

19. Marsh, A. P., and P. E. Martin. Effect of cycling experience, aerobic power and power output on preferred and most economical cycling cadences. Med. Sci. Sports Exerc. 29:1225-1232, 1997.

20. Matsui, H., K. Kitamura, and M. Miyamura. Oxygen uptake and blood flow of the lower limb in maximal treadmill and bicycle exercise. Eur. J. Appl. Physiol. 40:57-62, 1978.

21. Neptune, R. R., and M. L. Hull. A theoretical analysis of preferred pedaling rate selection in endurance cycling. J. Biomech. 32:409-415, 1999.

22. O'Toole, M. L., and P. S. Douglas. Applied physiology of triathlon. Sports Med. 19:251-267, 1995.

23. Patterson, R. P., and M. I. Moreno. Bicycle pedalling forces as a function of pedaling rate and power output. Med. Sci. Sports Exerc. 22:512-516, 1990.

24. Poole, D. C., and R. S. Richardson. Determinants of oxygen uptake. Sports Med. 24:308-320, 1997.

25. Saunders, M. J., E. L. Evans, S. A. Arngrimsson, J. D. Allison, G. L. Warren, and K. J. Cureton. Muscle activation and the slow component rise in oxygen uptake during cycling. Med. Sci. Sports Exerc. 32:2040-2045, 2000.

26. TAkaishi, T., T. Yamamoto, T. Y. Ono, and T. Moritani. Neuromuscular, metabolic and kinetic adaptations for skilled pedaling performance in cyclists. Med. Sci. Sports Exerc. 30:442-449, 1998.

27. Takaishi, T., Y. Yasuda, T. Ono, and T. Moritani. Optimal pedaling rate estimated from neuromuscular fatigue for cyclists. Med. Sci. Sports Exerc. 28:1492-1497, 1996.

28. Vercruyssen, F., C. Hausswirth, D. Smith, and J. Brisswalter. Effect of exercise duration on optimal pedaling rate choice in triathletes. Can. J. Appl. Physiol. 26:44-54, 2001.

29. Wasserman, K., B. J. Whipp, S. N. Koyal, and W. L. Beaver. Anaerobic threshold and respiratory gas exchange during exercise. J. Appl. Physiol. 35:236-243, 1973.

30. Woledge, R. C. Possible effects of fatigue on muscle efficiency. Acta Physiol. Scand. 162:267-273, 1998. 